\title{
The Poisson process with dead time captures important statistical features of neural activity
}

\author{
Moritz Deger*, Stefano Cardanobile, Moritz Helias and Stefan Rotter
}

Address: Bernstein Center for Computational Neuroscience Freiburg, Germany

Email: Moritz Deger* - deger@bccn.uni-freiburg.de

* Corresponding author

from Eighteenth Annual Computational Neuroscience Meeting: CNS*2009

Berlin, Germany. 18-23 July 2009

Published: 13 July 2009

BMC Neuroscience 2009, I0(SuppI I):PIIO doi:I0.II86/I47I-2202-I0-SI-PIIO

This abstract is available from: http://www.biomedcentral.com/I47I-2202/I0/SI/PI I0

(C) 2009 Deger et al; licensee BioMed Central Ltd.

\section{Poster presentation}

Stochastic point processes are widely used in computational neuroscience to model the spiking of single neurons and neuronal populations. The choice of a particular point process is critical for statistical measures of neural activity and has impact on the subthreshold dynamics of neuron models.

Here we show that the Poisson process with dead time, a particular simple point process, captures important features of the spiking statistics of neurons [1,2] (Fig. 1). On the level of single neurons, we apply a step change to the rate of a Poisson process with dead time, keeping the dead time constant. The expected PSTH is computed by numerically solving the partial differential equation of the corresponding non-homogeneous renewal process [3] and we also give an analytical approximation. We observe a very sharp transient in the firing-rate (Fig. 2) that resembles experimental results of [4].

On the level of neuronal populations, we employ the superposition of many Poisson processes with dead time as a model of the population activity in a network. We compute the explicit form of the inter-spike-interval (ISI) distribution and the coefficient of variation for superimposed processes and compare them to direct simulations. The ISIs of the superimposed spike trains show negative serial correlations that correspond to those we observe in population recordings of simulated integrate-and-fire neurons (Fig 3).

For the single Poisson process with dead time and superpositions alike, we can determine the variance of shot noise driven by them with the associated spike count in a certain time window or the free membrane potential of an

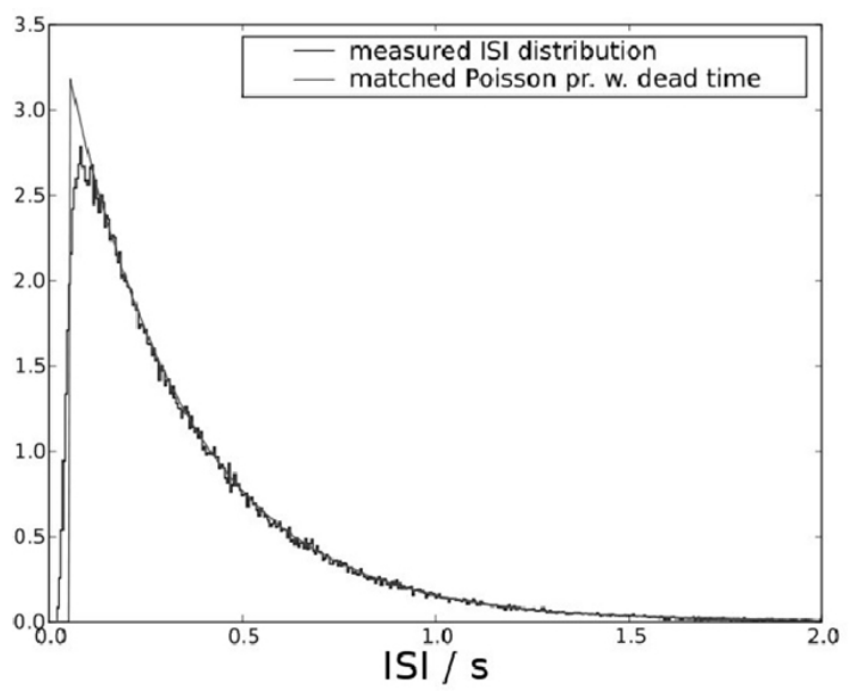

Figure I 


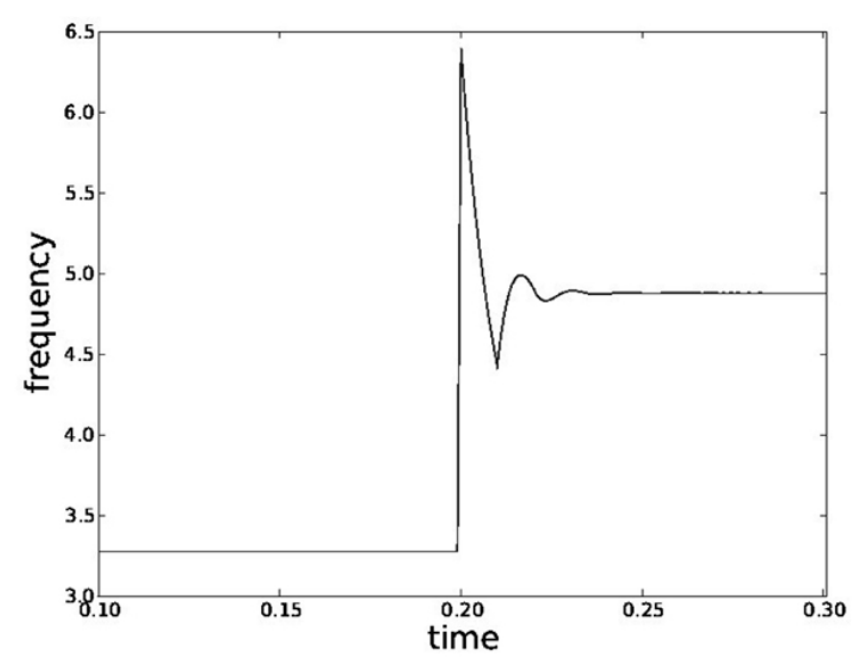

Figure 2

IF neuron. This enables us to show how empirical approximations of the Fano factor depend on the width of the counting window, and how the statistical properties of the driving point-process influence the variance of the subthreshold dynamics of neurons.

\section{Acknowledgements}

Partially funded by DIP FI.2 and BMBF Grant 0IGQ0420 to the Bernstein Center for Computational Neuroscience Freiburg.

\section{References}

I. Johnson D, Swami A: The transmission of signals by auditorynerve fiber discharge patterns. J Acoust Soc Am 1983:74.

2. Johnson $D$ : Point process models of single-neuron discharges. J Computational Neuroscience 1996:275-299.

3. Gerstner W, Kistler M: Spiking neuron models Cambridge University Press; 2002.

4. Mainen Z, Sejnowski T: Reliability of spike timing in neocortical neurons. Science 1995:268.

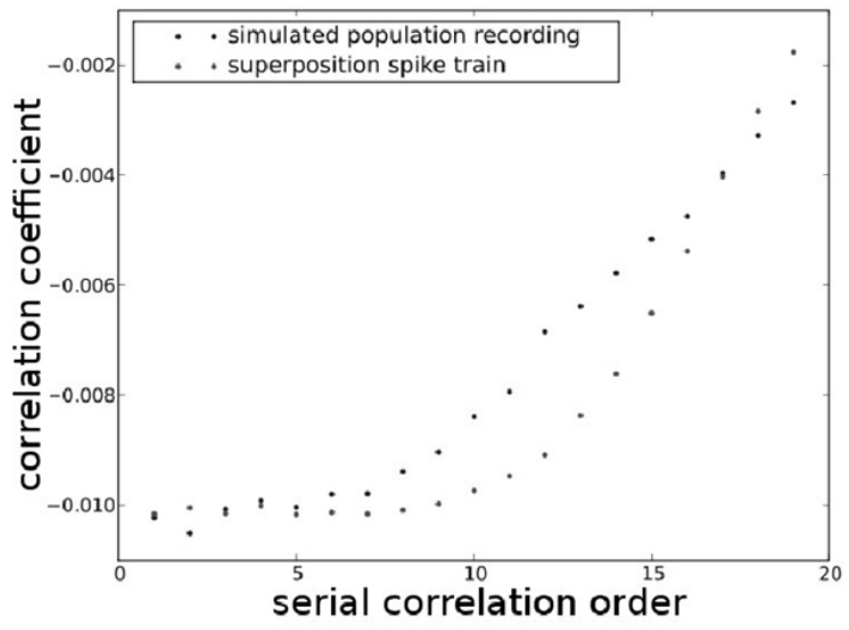

Figure 3
Publish with Bio Med Central and every scientist can read your work free of charge

"BioMed Central will be the most significant development for disseminating the results of biomedical research in our lifetime."

Sir Paul Nurse, Cancer Research UK

Your research papers will be:

- available free of charge to the entire biomedical community

- peer reviewed and published immediately upon acceptance

- cited in PubMed and archived on PubMed Central

- yours - you keep the copyright

Submit your manuscript here:

http://www.biomedcentral.com/info/publishing_adv.asp 